\title{
Índice de Centralidade de Representações Sociais a partir de Evocações (INCEV): Exemplo de Aplicação no Estudo da Representação Social sobre Envelhecimento
}

\author{
Social Representations Centrality Index from Evocations (INCEV): An Example \\ of Application on the Study of the Social Representation on Aging
}

\author{
João Fernando Rech Wachelke* \\ Università degli studi di Padova
}

\begin{abstract}
Resumo
O artigo propõe uma técnica para caracterizar a estrutura de representações sociais a partir de dados de evocações livres, o INCEV, um índice que avalia a centralidade de elementos representacionais levando em consideração sua freqüência, incondicionalidade e importância. Um estudo empírico foi realizado acerca da representação social do envelhecimento, comparando os resultados do INCEV com o das técnicas de análise prototípica de Vergès e questionamento (MEC). A coleta de dados principal ocorreu com uma amostra de 218 estudantes universitários, que responderam a um questionário de evocações sobre o termo envelhecimento e caracterizaram cada resposta acerca da importância e possibilidade do objeto manter sua identidade prescindindo-se da palavra fornecida. Os resultados do INCEV mostraram-se mais próximos do MEC que os derivados da análise prototípica. Conclui-se que o INCEV apresenta indícios de validade e pertinência, tendo como vantagem a incorporação de princípios da teoria do núcleo central no levantamento inicial da representação.

Palavras-chave: Abordagem estrutural; representações sociais; evocações; envelhecimento.
\end{abstract}

\begin{abstract}
The article proposes a technique to describe social representations structure from free evocation data, the INCEV, an index which evaluates representational element centralities taking into account their frequencies, unconditionality and importance. An empiric study was carried out concerning the social representation on aging, comparing INCEV results to those of Vergès' prototypical analysis and questioning (MEC) techniques. The main data collection took place with a sample of 218 undergraduate students, who answered to an evocation questionnaire about the word aging and evaluated each response concerning importance and the possibility of the object keeping his/her identity without the provided word. INCEV results were closer to MEC's than those derived from prototypical analysis. It is concluded that the INCEV presents evidences of validity and pertinence, having as an advantage the inclusion of central core theory principles on the first representation description.

Keywords: Structural approach; social representations; evocations; aging.
\end{abstract}

A representação social tornou-se um construto sociopsicológico a partir do estudo de Moscovici (1961) sobre o pensamento social da sociedade francesa acerca da psicanálise, dando nova abordagem à noção de representação coletiva de Durkheim (1898). O fenômeno das representações sociais, objeto de estudo de pesquisadores da psicologia social, refere-se aos processos por meio dos quais os atores sociais dão significado à realidade, através da construção, compartilhamento e transformação de esquemas

\footnotetext{
* Endereço para correspondência: Rua Octavio Lebarbenchon, 69, Florianópolis, SC, Brasil, CEP 88037-290. E-mail: wachelke@yahoo.com

Agradecimentos: Alexsandro de Andrade, Jean Natividade, Kleber dos Santos, Rafael Wolter e Dr. Michel-Louis Rouquette pelos comentários e sugestões fornecidos.

O autor é bolsista da Fondazione Cassa di Risparmio di Padova e Rovigo.
}

simbólicos para compreender o ambiente do cotidiano em que vivem e orientar suas ações. Esse processo denominase pensamento social (Flament \& Rouquette, 2003), e dá origem a produções simbólicas que se prezam a funções diversificadas, conforme a extensão de compartilhamento, estabilidade e o tipo de objeto social a que se referem, entre outras dimensões de construto (Guimelli, 1999; Wolter \& Gurrieri, 2007).

Dentre esses produtos ou formas do pensamento social, podem-se mencionar as representações sociais. Trata-se de um conteúdo estruturado sobre um fenômeno ou objeto social relevante, que incorpora aspectos de natureza simbólica, cognitiva, avaliativa e afetiva, e é conscientemente compartilhado com outras pessoas (Wagner, 1998). Desde que Moscovici (1961) propôs o campo teórico das representações sociais, surgiu uma variedade de escolas com abordagens de estudo diferentes para os fenômenos de 
interesse. A escola estrutural do pensamento social entende a representação social como um sistema de unidades cognitivas organizadas numa estrutura de conhecimento (Abric, 1994a, 2001). É uma abordagem que preza por estudos experimentais (Abric, 1989; Moliner, 1994a) e que enfoca os processos que regulam formação e transformação de representações sociais (Flament, 1989; Moliner, 2001), bem como as relações entre práticas e comportamentos sociais e com outros construtos sociopsicológicos (Flament \& Rouquette, 2003; Guimelli, 1999; Moliner, 1996; Moliner \& Vidal, 2003; Rouquette, 2005; Tafani, 1997).

A principal teoria proposta pela escola estrutural é a teoria do núcleo central. Segundo ela, toda representação é formada por dois sistemas de cognemas (unidades cognitivas) (Codol, 1969): o núcleo ou sistema central e o sistema periférico. $\mathrm{O}$ núcleo central da representação compreende os elementos consensuais que definem a representação e organizam os demais elementos. Esses elementos geralmente são mais abstratos. O núcleo central tende à estabilidade, e uma mudança nesse sistema implica uma mudança de representação (Abric, 1976, 1994b; Abric \& Tafani, 1995).

Já o sistema periférico refere-se aos aspectos mais particulares da representação, por meio dos quais atores sociais isolados a adaptam a situações específicas do cotidiano. São elementos que tratam de aspectos mais individualizados, regidos pelos elementos centrais. Além disso, funcionam como esquemas de ação, guiando diretamente práticas sociais (Flament, 1994).

Descrever uma representação em termos estruturais, ao menos em sua essência, equivale a identificar os elementos que compõem o seu núcleo central. Há uma variedade de técnicas que servem para esses objetivos. Num primeiro estágio de investigação, faz-se necessário obter um levantamento acerca dos elementos da representação, geralmente por meio de entrevistas ou tarefas de associação livre (chamadas evocações ou evocações livres nas pesquisas sobre representações sociais). Posteriormente pode-se solicitar a participantes de pesquisa que façam parte da população de interesse que indiquem os aspectos mais característicos de um objeto social (questionário de caracterização); ou então que os agrupem em conjuntos (análise de similitude); que indiquem se a desconsideração do elemento permite manter a identidade do objeto social de interesse (técnica do questionamento, ou mise en cause); ou então que indiquem quais conectores lógicos ligam cada elemento ao objeto social (técnica dos esquemas cognitivos de base); dentre outras possibilidades (Abric, 2003; Bouriche, 2003; Guimelli \& Rouquette, 1992; Moliner, 1994b; Vergès, 2005).

Uma das técnicas mais utilizadas para a etapa de levantamento de elementos representacionais é a análise prototípica (Vergès, 1992). Trata-se de um procedimento realizado com evocações livres, em que se computam suas freqüências e ordem média com que aparecem no discurso em relação às demais palavras. Segundo a técnica, no conjunto das palavras com freqüências altas e que são evocadas nas primeiras posições encontram-se aquelas que prova- velmente constituem elementos que formam o núcleo, o que pode ser verificado com o auxílio de técnicas de teste de centralidade, como as mencionadas anteriormente. Uma modificação recente na técnica (Abric, 2003) sugere a substituição do emprego da ordem de evocação por um critério de ordem de importância fornecido pelo próprio respondente.

A análise prototípica, quando apresentada originalmente, seria apenas o primeiro passo de um procedimento mais completo de análise das co-ocorrências das palavras e de seu agrupamento em categorias temáticas, permitindo a identificação do núcleo da representação (Sá, 1996; Vergès, 1992). O próprio autor deixa claro que é necessária uma integração dos dados para obter resultados mais conclusivos.

Primeiramente, é preciso apontar que a análise prototípica fornece indicações com palavras brutas que freqüentemente não são diretamente elementos de representação social, mas que dizem respeito a um tema que englobaria aspectos específicos. Por exemplo, ao se realizar uma coleta de dados com o termo indutor "envelhecimento", respostas como "rugas" ou "cabelos brancos" não são propriamente elementos. Essas respostas mostram mais poder explicativo agrupadas sob um elemento mais geral denominado "sinais físicos" (Wachelke, 2007). De todo modo, no campo das representações sociais freqüentemente não há indicações unívocas para determinar as fronteiras e grau de generalidade dos cognemas constituintes das representações sociais, pois o seu enquadramento acaba por subordinar-se a decisões do pesquisador (Flament \& Rouquette, 2003).

Além disso, o critério da ordem de evocação não possui relações diretas com aspectos teóricos da teoria do núcleo. Para Vergès (1992), trata-se de um critério de relevância pessoal de uma palavra, que ele alia à dimensão da relevância compartilhada que se sustenta no critério de freqüência. Porém, trata-se sobretudo de um postulado, sem comprovação empírica. A adoção do critério de importância proposta por Abric (2003) aparenta ser mais compatível ao pelo menos associar a centralidade a um valor superior em relação aos demais elementos da representação, que está presente na teoria.

Mesmo com essas limitações, a análise prototípica tem sido adotada freqüentemente por pesquisadores como única etapa em investigações de núcleo central, tanto no campo da psicologia social como em outras disciplinas que fazem uso das teorias e técnicas de representações sociais. Como apontam os estudos de Arruda (2005) e Camargo, Wachelke e Aguiar (2007), a técnica das evocações é um dos procedimentos de análise textual mais utilizados em comunicações de pesquisa das Jornadas Internacionais sobre Representações Sociais, maior congresso científico da área que ocorre no Brasil. Ao analisar os resumos dessas Jornadas (Almeida, 2007; Arruda \& Sá, 2003; Madeira, 1998; Moreira, 2005; Nascimento-Schulze \& Camargo, 2001) confirma-se que, tal como aponta Jodelet (2005), o estudo das representações sociais, no Brasil, é majoritariamente realizado por profissionais e pesquisadores de áreas como saúde e educação que visam caracterizar um campo de intervenção profissional. 
O estudo das representações sociais no Brasil caracteriza-se, sobretudo, não pelo interesse de psicólogos sociais preocupados com a explicação de dimensões do processo de pensamento social, mas sim pela sua ligação com a ciência aplicada. Nesses casos, é de primeiro interesse a obtenção de informações diagnósticas acerca do conhecimento de um grupo social sobre um objeto qualquer, que possa resolver problemas de ordem prática, geralmente com elevada relevância social.

O recurso à análise prototípica isolada pode ser entendido em boa parte dos casos em que isso ocorre como indício de domínio inadequado de aspectos teóricos e metodológicos das representações. Porém há casos em que de há necessidade de prescindir de um retorno ao campo, seja devido à baixa viabilidade de realizar uma segunda coleta, seja pela necessidade de rápida tomada de decisões profissionais, como no caso de populações que estão submetidas a alguma espécie de risco. Assim, apresenta-se como pertinente a possibilidade de uma caracterização mais precisa da estrutura representacional, em termos de centralidade dos elementos, propiciada por uma única coleta, preferencialmente amparada por recursos que façam uso de investigações que diferenciam elementos centrais de periféricos, incorporando qualidades de técnicas como o mise en cause, que tem apontado resultados consistentes.

O presente estudo apresenta uma técnica de caracterização estrutural de representações sociais alinhada com esses princípios. Seu objetivo é descrever os princípios e procedimentos associados a essa técnica e avaliá-la por meio de um exemplo de aplicação. Trata-se de um índice que pondera os critérios de frequiência dos elementos por uma proporção do que chamaremos valor simbólico pessoal, uma característica que tem como pré-requisitos o entendimento por parte do ator social de que uma resposta de evocação livre seja simultaneamente essencial para a caracterização do objeto social e tenha alta importância. Assim, fundamentalmente substitui-se o critério de ordem de evocação por outros mais alinhados com a teoria do núcleo central.

Enquanto contexto de investigação busca-se caracterizar a representação social de universitários sobre envelhecimento. Estudos sobre representações sociais de jovens e adultos não-idosos sobre envelhecimento apontam que os elementos da representação organizam-se em pólos opostos de um eixo de perdas e ganhos, referindo-se a um contraste entre o enfraquecimento, surgimento de sinais físicos e doenças e uma aproximação da morte, de um lado, e o reconhecimento da sabedoria do idoso e da constatação de que de modo geral envelhecer significa ter uma vida mais tranquiila (Santos \& Meneghin, 2006; Wachelke et al., 2007). Além disso, as representações sociais desses grupos sobre o idoso apontam para a figura de uma pessoa frágil, discriminada, doente, carente e dependente, mas que deve ser respeitada por sua história e sabedoria (Martins, 2002; Mithidieri \& Tura, 2003). O envelhecimento é concebido como um processo que gera sabedoria, mas ao mesmo tempo acompanhado por crescente desconforto, solidão, adoecimento e enfraquecimento (Gastaldi \&
Contarello, 2006). A velhice é uma etapa natural da vida, marcada por degradação física e mental, mas também aumento de sabedoria (Martins, 2002).

Em termos estruturais, o estudo de Mithidieri e Tura (2003) foi uma caracterização da representação social do idoso em estudantes de medicina. Após análise prototípica houve indícios de provável centralidade do elemento sabedoria, mas também foi constatada a existência de uma sobreativação de elementos periféricos do eixo das perdas, como frágil, discriminado, doença e morte. Junto a uma amostra de estudantes de enfermagem, após combinação de análise prototípica com análise de similitude, Wachelke (2007) também apontou que o elemento com maior probabilidade de ser central é sabedoria, no contexto do estudo denominado como sabedoria e experiência.

\section{Método}

\section{Participantes}

Os participantes do estudo foram 218 estudantes universitários de graduação da Universidade Federal da Paraíba, sendo $119(54,6 \%)$ do sexo feminino. A média de idade foi de 22 anos e 6 meses, com mediana de 21 anos e desvio padrão de 4 anos e 10 meses. Foi contemplado um universo de 15 cursos de graduação (66 participantes de cursos de ciências exatas, 68 de ciências da saúde e 84 de ciências humanas), de períodos variados. Optou-se por fazer um estudo com universitários porque essa população é formada em grande parte por jovens com alto nível de escolaridade, o que os torna aptos para responder tarefas que exijam algum nível de abstração, como freqüentemente são os questionários de representações sociais. A amostra do estudo foi de conveniência, buscando abarcar uma variedade de cursos universitários de áreas diversas, os quais não possuíam disciplinas dedicadas especificamente ao estudo do envelhecimento em suas grades curriculares obrigatórias. A maior quantidade de estudantes de ciências humanas deve-se a uma maior presença de estudantes em sala de aula nas coletas realizadas junto aos cursos dessa área, a qual não foi planejada.

\section{Instrumento}

Foi empregado um questionário de evocação livre, contendo a seguinte instrução: "escreva as cinco primeiras palavras ou expressões que lhe vem à cabeça ao pensar em 'envelhecimento"'. Cada uma das respostas era enumerada, e em seguida o questionário solicitava aos participantes que classificassem cada resposta como "pouco importante" ou "muito importante". Essa questão consistia numa avaliação acerca da importância da resposta. Por fim, uma última tarefa determinava que os participantes avaliassem a incondicionalidade de cada resposta. Para tanto havia a seguinte instrução: "é possível pensar em envelhecimento sem pensar na 'palavra 1'?'. Uma resposta negativa implica uma avaliação de que a resposta faz referência a um elemento essencial da representação.

Além dessas questões, foram incluídos itens de caracterização acerca da idade, sexo e curso dos respondentes. 
Por fim, o questionário também trazia um item buscando caracterizar a implicação dos participantes com o objeto social envelhecimento, por meio do grau de convívio com idosos. Assim os participantes deveriam indicar a alternativa mais próxima de sua realidade, dentre as seguintes: 1. pouco convívio com idosos; 2. convívio ocasional com idosos no trabalho ou cotidiano; e 3 . convívio com idosos na própria residência.

\section{Procedimento e Análise dos Dados}

Após contato com os professores responsáveis por disciplinas de cursos de graduação da universidade, os questionários foram aplicados coletivamente por duplas de assistentes de pesquisa treinados pelo autor, em salas e horários de aula, após o fornecimento de instruções em breve exposição. Foram seguidos os procedimentos éticos de pesquisa com seres humanos. A participação foi voluntária, anônima e individual. $\mathrm{O}$ estudo insere-se em projeto avaliado pelo Comitê de Ética e Pesquisa com Seres Humanos (CEPSH) da Universidade Federal de Santa Catarina (UFSC), tendo sido aprovado com o número de protocolo 326/06.

Para a análise de dados, primeiramente foi efetuada a análise prototípica (Vergès, 1992), cruzando-se os critérios de ordem média de evocação e freqüência. Segundo essa análise, palavras com uma freqüência elevada em comparação com as demais, e que tenham ordens médias de aparição no discurso baixas, compõem o primeiro quadrante (também chamado quadrante do núcleo central), constituindo um conjunto em que provavelmente se encontrariam os elementos centrais da representação. No presente caso, a análise foi realizada com palavras brutas, agrupadas somente em caso de semelhança de radical e sem alteração de significado essencial. A análise foi processada no programa Evocation (Vergès, Scano, \& Junique, 2002).

Em seguida, foram realizados os procedimentos de cálculo do índice proposto para análise, um índice de centralidade de elementos de representações sociais a partir de evocações, doravante chamado INCEV. Antes de calcular o índice propriamente dito, foi determinada a freqüência de cada palavra no corpus $\left(F_{t}\right)$, permitindo-se apenas agrupamento de formas com base na semelhança de radical que não alterem o sentido essencial da palavra. Expressões foram consideradas como uma única forma. Observandose as formas que ocorrem em pelo menos $5 \%$ da amostra, tem-se uma noção daquelas que podem ser agrupadas, dando origem mais propriamente a categorias que correspondem a elementos representacionais ao fim da análise. É recomendável construir as categorias baseando-se nas formas mais frequientes, de modo a dar a elas validade no contexto de pesquisa, não sobrevalorizando palavras com ocorrências pouco expressivas.

A seguir, calculou-se a proporção dos participantes que consideraram cada palavra simultaneamente muito importante e essencial para o objeto social (adaptação do princípio de refutação da técnica de mise en cause), dentre os participantes que citaram cada palavra. Quando as duas condições são satisfeitas para um participante, conside- ra-se que essa resposta tem para ele alto valor simbólico pessoal, ou seja, possui uma ligação simbólica importante para com o objeto envelhecimento, mostrando-se simultaneamente essencial para sua concepção (incondicionalidade) e importante. A proporção de casos com alto valor simbólico pessoal em relação ao total de ocorrências da palavra $\left(P_{v s}\right)$ fornece uma medida das características de centralidade potencial de uma representação para um grupo, obtida pela divisão das ocorrências da forma em que foram respeitados os dois requisitos $\left(F_{r}\right)$ pelo total de ocorrências da forma $\left(F_{t}\right)$, isto é, $P_{v s}=F_{r} / F_{t}$.

Por fim, coube agrupar as formas em elementos respeitando as palavras com maiores frequiências, o sentido semântico e também a proporção de centralidade pessoal. Formas diferentes só devem ser combinadas num único elemento se tiverem significados próximos e proporções não muito discrepantes (de modo a traçar alguns limites objetivos, uma tolerância de 0,2 pode ser sugerida na $P_{v s .}$, deixando transparecer, evidentemente, a arbitrariedade desse critério).

$\mathrm{O}$ valor do INCEV é obtido tomando-se as ocorrências de cada elemento em que as condições de alto valor simbólico pessoal são respeitadas $\left(F_{r}\right)$, e dividindo-as pelo universo de pesquisa, no caso, o total de participantes, que pondera o critério de valor simbólico pessoal do elemento pelo nível de compartilhamento na amostra. Assim, o INCEV é calculado por $F_{r} / N$, ou a divisão das ocorrências com alto valor simbólico pessoal pelo total de participantes. Tem-se um resultado que varia de 0 a 1 .

O INCEV foi calculado para os elementos com freqüências relevantes para a amostra (por exemplo, igual ou maior que $5 \%$ do total de participantes). Parte-se do pressuposto que quanto maior for o valor do índice para um dado elemento, mais provável a centralidade desse elemento para a representação social.

Os cálculos das proporções foram realizados por meio da adaptação de uso dos sub-programas constituintes do mesmo programa utilizado para a análise prototípica, Evocation. Posteriormente os resultados foram transportados para uma planilha Excel, para se chegar aos resultados por elemento.

\section{Resultados}

A análise prototípica foi realizada para obter-se uma primeira caracterização da estrutura conforme uma técnica difundida de levantamento de elementos de representação social. A ordem média de evocação foi calculada com formas com freqüências iguais ou maiores a 11 , ou seja, $5 \%$ do total de participantes, resultando na ordem média 3. A frequiência intermediária foi de 28 , correspondente a 276 evocações ou 25,4\% do total de 1085 . Esse ponto de corte foi determinado pelo estudo da distribuição das freqüências, sendo constatada a existência de uma passagem de $25,4 \%$ para $30,4 \%$ da freqüência 28 para 29, o que indica uma diferença qualitativa entre essas duas marcas. A Tabela 1 apresenta os resultados da análise prototípica. 
Psicologia: Reflexão e Crítica, 22(1), 102-110.

Tabela 1

Análise Prototípica Referente às Evocações de Universitários sobre a Representação Social acerca de Envelhecimento

\begin{tabular}{lllllll}
\hline & Elemento & OME $<3$ & & & OME $>3$ \\
$f$ & $f$ & OME & Elemento & $f$ & OME \\
\hline$f>=28$ & experiência & 78 & 2,33 & morte & 38 & 3,45 \\
& doença & 59 & 2,71 & & & \\
& sabedoria & 44 & 2,66 & & & \\
aposentadoria & 29 & 2,48 & & & \\
& solidão & 28 & 2,64 & & & \\
$f<28$ & & & & & \\
& saúde & 27 & 2,82 & família & 27 & 3,17 \\
& conhecimento & 26 & 2,62 & respeito & 18 & 3,12 \\
& maturidade & 24 & 2,42 & fragilidade & 17 & 3,73 \\
& rugas & 21 & 2,24 & cuidado & 15 & 3,01 \\
& idade & 16 & 1,63 & cansaço & 13 & 3,31 \\
& descanso & 15 & 2,93 & netos & 13 & 3,08 \\
& amadurecimento & 14 & 1,93 & vida & 13 & 3,01 \\
& idoso & 14 & 2,07 & abandono & 11 & \\
& tristeza & 12 & 2,92 & & & \\
\end{tabular}

As palavras que constam no primeiro quadrante são $e x$ periência, doença, sabedoria, aposentadoria e solidão. A distribuição de freqüências sugere que experiência, doen$c ̧ a$ e sabedoria sejam centrais, pois há uma diferença em relação às demais palavras do quadrante, que estão mais próximas da freqüência intermediária. No quadrante de altas freqüências e altas ordens de evocação, há somente o elemento morte, que possui freqüência que o coloca em posição intermediária entre o bloco de experiência, doença e sabedoria e as palavras aposentadoria e solidão, ou seja, dá possibilidade de centralidade ao elemento morte se for considerado que o critério de ordem de evocação é mais polêmico que o de freqüência.

Uma análise acerca desses resultados sugeriria a necessidade de integrar as palavras experiência e sabedoria, formando um elemento combinado, já que os dois termos ocupam espaços próximos no campo semântico. Assim os resultados da análise prototípica acerca de hipóteses de centralidade indicam que haveria dois elementos provavelmente centrais: experiência e sabedoria, o mais central, e doença.

Em seguida passou-se ao cálculo do INCEV. A Tabela 2 indica as palavras evocadas por pelo menos 5\% (11) dos participantes.

Os resultados apontam a possibilidade de agrupar algumas dessas palavras em elementos mais abrangentes da representação social. Assim, o elemento experiência e sabedoria passaria a integrar as palavras experiência, sabedoria, maturidade, conhecimento e amadurecimento. $\mathrm{O}$ elemento solidão incorporaria as palavras solidão e abandono. A palavra idade foi agrupada junto a outros vocábulos referentes a períodos de tempo (como passado, futuro, e assim por diante), formando o elemento passagem do tempo. O elemento família agruparia as palavras família e netos. Além desses casos, as palavras mais evocadas pre-
Tabela 2

Freqüências das Palavras Mencionadas por pelo menos 5\% dos Participantes

\begin{tabular}{ll}
\hline Palavra & Freq. \\
\hline experiência & 78 \\
doença & 59 \\
sabedoria & 44 \\
morte & 38 \\
aposentadoria & 28 \\
solidão & 28 \\
família & 27 \\
saúde & 27 \\
conhecimento & 26 \\
maturidade & 23 \\
rugas & 21 \\
respeito & 18 \\
fragilidade & 17 \\
cuidado & 15 \\
descanso & 15 \\
idade & 15 \\
amadurecimento & 14 \\
cansaço & 14 \\
idoso & 13 \\
netos & 13 \\
vida & 13 \\
tristeza & 12 \\
abandono & 11 \\
\hline
\end{tabular}

sentes na Tabela 2 serviram de base para constituir elementos por meio da incorporação das palavras menos evocadas; é o caso de rugas que foi agrupada junto à expressão cabelos brancos para formar o elemento sinais 
físicos. A palavra filhos, também mencionada por menos de 11 participantes, foi incorporada ao elemento família.

Em posse das proporções de alto valor simbólico $\left(P_{v s}\right)$ de cada elemento, foi possível decidir pelo agrupamento ou não das palavras aos elementos. Decidiu-se pelo agrupamento no caso de proporções próximas e similaridade semântica.

Os cálculos foram refeitos, considerando-se o agrupamento de palavras em elementos. Com base nos resultados dessa segunda análise, foram calculados os INCEV para os elementos. A Tabela 3 apresenta os resultados.

\section{Tabela 3}

Centralidade dos Elementos da Representação Social de Universitários sobre Envelhecimento segundo os valores do INCEV, Percentual de Evocação de cada Elemento em Relação ao Total de Participantes e Percentual Relativo à Proporção de Ocorrências de Alto Valor Simbólico para cada Elemento $\left(P_{c}\right)$

\begin{tabular}{lc}
\hline Elemento & INCEV $\left(\%\right.$ freq.; $\left.\% P_{v s}\right)$ \\
\hline experiência e sabedoria & $0,63(56 ; 68)$ \\
doença & $0,17(33 ; 50)$ \\
família & $0,13(23 ; 56)$ \\
saúde & $0,13(16 ; 80)$ \\
morte & $0,11(21 ; 48)$ \\
cuidados & $0,09(11 ; 87)$ \\
passagem do tempo & $0,09(14 ; 65)$ \\
aposentadoria & $0,08(13 ; 62)$ \\
solidão & $0,07(22 ; 31)$ \\
descanso e lazer & $0,06(17 ; 38)$ \\
fragilidade & $0,04(11 ; 36)$ \\
idoso & $0,04(11 ; 35)$ \\
sinais físicos & $0,03(17 ; 17)$ \\
\hline
\end{tabular}

Foram calculados os valores INCEV para os elementos com freqüências iguais ou maiores ao equivalente a $10 \%$ da amostra. Por definição, o INCEV apresenta valores decrescentes numa escala de centralidade. O estatuto do elemento experiência e sabedoria como central é evidente devido à diferença no índice em relação a doença, o elemento com o segundo maior valor. Porém, observando os índices referentes aos demais elementos não há clareza de quais elementos seriam centrais, pois eles possuem valores próximos que diminuem gradativamente.

Nesse ponto, sugerem-se dois critérios para facilitar a diferenciação entre elementos centrais e periféricos. $\mathrm{O}$ primeiro deles refere-se a um valor crítico de distinção entre centrais e periféricos. Nesse ponto um valor arbitrário pode ser de ajuda, mesmo reconhecendo que as representações sociais não podem ter sua lógica completamente capturada segundo um princípio exato tão simples como o do INCEV, e sabendo que se incorre, portanto, numa simplificação. Considerando-se que, segundo a perspectiva adotada, a proporção de centralidade de um elemento central deveria ser pelo menos maior que a metade, foi adotada uma possível $P_{v s}$ de 0,51 como mínima.
Além disso, parece razoável supor que um elemento central seja mencionado por pelo menos um quinto da amostra $(0,20)$. Dado que uma outra maneira de chegar a $F_{r} / N$ é pelo produto da proporção de ocorrência de um elemento no total de participantes pela proporção de alto valor simbólico pessoal, multiplicando-se 0,20 por 0,51 chega-se ao resultado arredondado de 0,10 . Segundo esse critério, elementos com INCEV igual ou maior a 0,10 seriam considerados centrais; aqueles com valores inferiores próximos a esse valor seriam periféricos salientes ou sobreativados, e aqueles com valores bem abaixo, periféricos comuns.

Outro ponto que não pode ser ignorado é que o cálculo do INCEV pode mascarar propriedades dos elementos que os desqualificariam como centrais. Assim, é importante não classificar elementos com freqüências altas de ocorrência de condições de alto valor simbólico e, contudo, baixas proporções em relação ao total de ocorrências do elemento, como centrais. Considerando que a freqüência pode ter um valor desproporcional no índice no caso de elementos com freqüências muito altas, deve-se adotar como condição indispensável para classificação de um elemento como centralidade o fato dele possuir pelo menos proporção de centralidade pessoal maior que a metade, ou seja, 0,51 ou mais. Ao respeitar esses dois critérios, INCEV 0,10 e $P_{v s}$ 0,51 ou mais, há sustentação suficiente para caracterizar a estrutura da representação no que diz respeito à centralidade dos elementos com base no índice proposto.

Segundo essas diretrizes, os elementos centrais da representação social do envelhecimento seriam experiência e sabedoria, família e saúde; ou seja, para os estudantes investigados, envelhecimento é um processo em que fundamentalmente a pessoa possui conhecimentos acumulados ao longo da vida, que se traduzem em maior sabedoria, e que é marcado pelo convívio familiar e cuidados e busca pela saúde. De todo modo, os elementos periféricos sobreativados condicionam o pensamento acerca desse objeto social, apontando para aspectos de conotação negativa que podem vir a marcar o envelhecimento, como o surgimento de doenças e a realidade da morte. Há ênfase também na necessidade de cuidados especiais decorrentes do processo, e de sua dimensão cronológica, bem como de ele marcar o fim da vida de trabalho, por meio da aposentadoria.

Esses são resultados um tanto diferentes dos fornecidos pela análise prototípica. Além de negarem a doença o estatuto central, diferentemente do que ocorreria conforme os resultados da primeira análise, cabe apontar que as palavras saúde e família, de acordo com a primeira análise, estariam nos quadrantes de baixas freqüências segundo os critérios prototípicos. Família estaria mesmo no quadrante da periferia propriamente dita. Assim, quais seriam os resultados mais próximos de um diagnóstico de centralidade preciso?

Para verificar isso, foi realizado, junto a uma outra amostra de 157 estudantes da mesma universidade $(49,7 \%$ do sexo feminino, 31,2\% de cursos de saúde, $35,7 \%$ de exatas e $32,5 \%$ de humanas), um teste de centralidade com a técnica do mise en cause (MEC) (Moliner, 1994b). Adotando-se sugestão de Milland (2001), foi definido como 
requisito mínimo para se considerar central um elemento uma taxa de refutação de $80 \%$. Decidiu-se por considerar os elementos com taxas entre 75 e $79 \%$ como periféricos sobreativados. Os elementos foram testados por meio de itens com enunciados tais como o seguinte, que se refere ao elemento doença: é possível pensar em envelhecimento sem pensar no surgimento de doenças? As opções de resposta foram: certamente sim, provavelmente sim, provavelmente não, certamente não. Os itens foram dicotomizados em sim e não, sendo que a taxa de refutação, ou de confirmação de centralidade, refere-se ao percentual de respostas de teor negativo.

As taxas de refutação dos elementos foram as seguintes: saúde - 94\%, família - 89\%, sinais físicos - 83\%, experiência e sabedoria - $82 \%$ (elementos que se qualificam como centrais), e passagem do tempo - 77,1\% e morte$75 \%$ (periféricos sobreativados). Outros elementos periféricos com altas taxas de refutação foram perdas $-72 \% \mathrm{e}$ aposentadoria $-70 \%$. O elemento doença teve taxa de refutação de apenas 55,1\%. Comparando-se os resultados da análise prototípica, INCEV e MEC, observa-se que o INCEV apresentou resultados mais próximos do MEC que a análise prototípica.

Por fim, buscou-se explorar usos complementares do INCEV na primeira amostra. Ele permite diferenciar grupos quanto à estrutura por meio de diferenças de valores do índice. É o que foi realizado a respeito da variável de implicação que foi incluída no questionário, o grau de convívio com idosos. Os dados foram agrupados conforme essa variável e o INCEV foi calculado para cada nível de convívio. Dos participantes, 77 não conviviam freqüentemente com idosos (grau de convívio 1), 106 conviviam ocasionalmente no cotidiano (grau 2) e 35 moravam com idosos em casa (grau 3). A Figura 1 traz os resultados de alguns elementos que se diferenciaram quanto a essa variável.

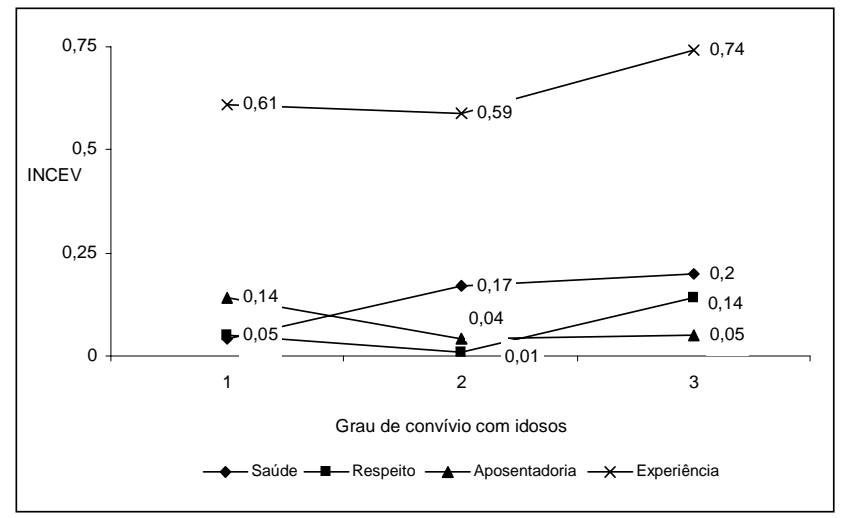

Figura 1. Diferenças na estrutura da representação social conforme o grau de convívio com idosos

Assim, constata-se que, a respeito da dinâmica da representação social do envelhecimento, em termos de sua estrutura, quando os participantes convivem com idosos em suas residências, aumenta a importância do elemento experiência e sabedoria na representação, que se torna ain- da mais central. Além disso, o elemento saúde cresce progressivamente em centralidade conforme aumenta o convívio com idosos, bem como respeito. São resultados que apontam no sentido de que o convívio com idosos modifica o pensamento social na direção de uma maior estruturação da representação em termos de elementos ligados a ganhos decorrentes do envelhecimento, bem como uma maior vivência acerca das preocupações e necessidades dos idosos quanto a saúde. Já o elemento aposentadoria encontra-se mais ativado entre participantes com pouco convívio com idosos, perdendo importância à medida que aumenta o grau de convívio.

\section{Discussão}

Ao realizar uma avaliação do INCEV é pertinente apontar que sua principal finalidade reside num maior aproveitamento da situação de levantamento inicial de elementos de representações sociais por meio de questionários. Esse levantamento pode ocorrer de diversas formas, inclusive por meio de entrevistas em profundidade ou consulta à literatura acadêmica (Sá, 1996), porém técnicas de evocação livre como a análise prototípica de Vergès (1992) e o INCEV permitem uma otimização dessa primeira coleta ao já viabilizar um primeiro nível de caracterização estrutural desses elementos, o que não ocorre em procedimentos centrados puramente no conteúdo.

Nesse sentido, cabe ressaltar que técnicas de levantamento desse tipo não substituem os procedimentos clássicos para confirmar a centralidade de elementos de representações (Moliner, 1994b), ou mesmo procedimentos que pautam por maior complexidade na investigação de relações entre cognemas como os esquemas cognitivos de base (Guimelli \& Rouquette, 1992). Testes de centralidade desse tipo permitem a utilização de procedimentos de estatística inferencial com maior propriedade, enquanto que técnicas de levantamento costumam restringir-se a possibilidades mais voltadas para o nível descritivo. Além de tudo, projetos completos de pesquisa só devem empregar técnicas de levantamento num primeiro momento, e se o objetivo é caracterizar com precisão uma estrutura de representação, é essencial fazer-se valer de procedimentos confirmatórios.

Com base em suas limitações, talvez o uso das técnicas de levantamento de elementos deva se restringir a apenas dois casos: (a) a primeira etapa de caracterização de representações sociais em projetos de pesquisa; (b) emprego por meio de profissionais que se utilizem de técnicas de caracterização de representações sociais para diagnósticos gerais. Nesse segundo caso, deve-se estar ciente da relativa superficialidade da técnica.

Feitas essas considerações, o INCEV apresenta-se como uma alternativa promissora para a etapa de levantamento, pois apresentou resultados mais próximos do MEC que a análise prototípica. Dado que o MEC é já uma técnica consagrada de teste de centralidade, observou-se que o INCEV diferenciou-se da análise prototípica ao indicar a centralidade dos elementos saúde e família, que não foram apontados no procedimento clássico. Além disso, foi ne- 
Wachelke, J. F. R. (2009). Índice de Centralidade de Representações Sociais a partir de Evocações (INCEV): Exemplo de Aplicação no Estudo da Representação Social sobre Envelhecimento.

gado o estatuto central do elemento doença; ainda que provavelmente devido a uma flutuação do acaso (afinal, a diferença de 0,50 para o requisito determinado de 0,51 na $P_{v s}$ é mínima), a proporção próxima de $50 \%$ já serviria como indicador de que a importância desse elemento não se equipara a de um elemento central.

Ambas as técnicas, INCEV e análise prototípica, não apontaram a centralidade de sinais físicos. Caberia verificar a que ponto sinais físicos é um elemento central de fato, explorando limitações da técnica de MEC, ou mesmo caracterizar a sua posição no sistema central por meio de estudos futuros; considerando o sistema bidimensional de Moliner (1995), a carga afetiva dos elementos de representação social constitui uma segunda dimensão estrutural pertinente. Desse modo, caso seja constatado que sinais físicos é um elemento com baixa carga afetiva, tratar-se-ia de um elemento central e neutro, o que o situaria no campo das definições. Outra maneira de pôr à prova o papel de sinais físicos na estrutura da representação seria por meio dos esquemas cognitivos de base (Guimelli \& Rouquette, 1992), já que se sabe que elementos centrais ativam mais conectores lógicos ligados que os elementos periféricos; poder-se-ia também observar quais tipos de conectores são ativados por esse elemento para compreender melhor o funcionamento do núcleo central da representação.

Em síntese, o INCEV apresenta-se como uma boa técnica para ser empregada como alternativa à análise prototípica no momento de levantamento de elementos de representações sociais. Sua vantagem reside na incorporação, na sua operacionalização, de princípios teóricos diretamente relacionados com a teoria do núcleo central. Além disso, a técnica pode ser aprimorada pelo acréscimo de coordenadas relacionadas a dimensões complementares de interesse à abordagem estrutural, como a carga afetiva ou a ativação de esquemas lógicos relativos a cada resposta, fortalecendo o levantamento com características oriundas de avanços téoricos e metodológicos derivados dos esquemas cognitivos de base e do modelo bidimensional. Uma operacionalização desse tipo provavelmente seria bem sucedida com questões semelhantes às empregadas com a importância e incondicionalidade no presente estudo, ou seja, voltadas para a avaliação da neutralidade ou afetividade (e também em qual sentido, negativo ou positivo) de cada resposta, ou se a resposta implicaria uma idéia de descrição, atividade ou avaliação. Cálculos semelhantes ao que foi proposto para $P_{v s}$ dariam conta de coordenadas independentes que poderiam ser analisadas de modo análogo, e assim dariam mais evidências da estrutura da representação já numa etapa de levantamento, indo além da centralidade.

\section{Referências}

Abric, J.-C. (1976). Jeux, conflits et représentations sociales. Unpublished doctoral dissertation, Université de Provence, Aix-en-Provence, France.

Abric, J.-C. (1989). L'étude expérimentale des représentations sociales. In D. Jodelet (Ed.), Les représentations sociales (pp. 187-203). Paris: PUF.
Abric, J.-C. (1994a). L'organisation interne des représentations sociales: système central et système périphérique. In C. Guimelli (Ed.), Structures et transformations des représentations sociales (pp. 73-84). Lausanne, Switzerland: Delachaux et Niestlé.

Abric, J.-C. (Ed.). (1994b). Pratiques sociales et représentations. Paris: PUF.

Abric, J.-C. (2001). L'approche structurale des représentations sociales: développements récents, Psychologie et Société, 2(4), 81-104.

Abric, J.-C. (2003). La recherche du noyau central et de la zone muette des représentations sociales. In J.-C. Abric (Ed.), Méthodes d'étude des représentations sociales (pp. 59-80). Ramonville Sant-Agne, France: Érès.

Abric, J.-C., \& Tafani, E. (1995). Nature et fonctionnement du noyau central d'une représentation sociale: la représentation de l'entreprise. Les Cahiers Internationaux de Psychologie Sociale, 28, 22-31.

Almeida, A. M. O. (Ed.). (2007). Anais da V Jornada Internacional e III Conferência Brasileira sobre Representações Sociais. Brasília, DF: Universidade de Brasília.

Arruda, A. (2005). Pesquisa em representações sociais: A produção em 2003. In M. S. S. Menin \& A. M. Shimizu (Eds.), Experiência e representação social (pp. 59-92). São Paulo, SP: Casa do Psicólogo.

Arruda, A., \& Sá, C. P. (Eds.). (2003). Anais da III Jornada Internacional e I Conferência Brasileira sobre Representações Sociais. Rio de Janeiro, RJ: Universidade do Estado do Rio de Janeiro.

Bouriche, B. (2003). L'analyse de similitude. In J.-C. Abric (Ed.), Méthodes d'étude des représentations sociales (pp. 221-252). Ramonville Sant-Agne, France: Érès.

Camargo, B. V., Wachelke, J. F. R., \& Aguiar, A. (2007). Desenvolvimento metodológico das pesquisas sobre representações sociais em jornadas internacionais de 1998 a 2005. In A. S. P. Moreira \& B. V. Camargo (Eds.), Contribuições para a teoria e o método de estudo das representações sociais (pp. 181202). João Pessoa, PB: Editora da Universidade Federal da Paraíba.

Codol, J.-P. (1969). Représentation de soi, d'autrui et de la tâche dans une situation sociale. Psychologie Française, 14, 217-228.

Durkheim, D. E. (1898). Représentations individuelles et représentations collectives. Revue de Métaphysique et de Morale, 6, 273-302.

Flament, C. (1989). Structure et dynamique des représentations sociales. In D. Jodelet (Ed.), Les représentations sociales (pp. 204-218). Paris: PUF.

Flament, C. (1994). Aspects périphériques des représentations sociales. In C. Guimelli (Ed.), Structures et transformations des représentations sociales (pp. 85-118). Lausanne, Switzerland: Delachaux Niestlé.

Flament, C., \& Rouquette, M.-L. (2003). Anatomie des idées ordinaires. Paris: Armand Colin.

Gastaldi, A., \& Contarello, A. (2006). Una questione di età: rappresentazioni sociali dell'invecchiamento in giovani e anziani. Ricerche di Psicologia, 20(4), 7-22.

Guimelli, C. (1999). La pensée sociale. Paris: PUF.

Guimelli, C., \& Rouquette, M.-L. (1992). Contribution du modèle associatif des schèmes cognitifs de base à l' analyse structurale des représentations sociales. Bulletin de Psychologie, 45(405), 196-202.

Jodelet, D. (2005). Representações sociais: História e avanços teóricos. Vinte anos da teoria das representações sociais no Brasil. In D. C. Oliveira \& P. H. F. Campos (Eds.), Representações sociais, uma teoria sem fronteiras (pp. 11-21). Rio de Janeiro, RJ: Museu da República. 
Madeira, M. C. (Ed.). (1998). Anais da I Jornada Internacional sobre Representações Sociais: Teoria e campos de aplicação. Natal, RN: Universidade Federal do Rio Grande do Norte.

Martins, C. R. M. (2002). O envelhecer segundo adolescentes, adultos e idosos usuários do SESC Maringá: Um estudo de representações sociais. Dissertação de Mestrado nãopublicada, Universidade Federal de Santa Catarina, Florianópolis, SC.

Milland, L. (2001). De la dynamique des rapports entre représentations sociales du travail et du chômage. Unpublished doctoral dissertation, Université de Provence, Aix-en-Provence, France.

Mithidieri, O. B., \& Tura, L. F. R. (2003). Os sentidos de idoso para estudantes de medicina: Subsídios para a seleção de conteúdos curriculares. In III Jornada Internacional e II Conferência Brasileira sobre Representações Sociais: Textos completos (pp. 605-619). Rio de Janeiro, RJ: Editora da Universidade do Estado do Rio de Janeiro.

Moliner, P. (1994a). L'etude experimentale des processus représentationnels. Commentaire de l'article de R. Michit. Papers on Social Representations, 3, 118-122.

Moliner, P. (1994b). Les méthodes de repérage e d'identification du noyau des représentaions sociales. In C. Guimelli (Ed.), Structures et transformations des représentations sociales (pp. 199-232). Lausanne, Switzerland: Delachaux et Niestlé.

Moliner, P. (1995). A two-dimensional model of social representations. European Journal of Social Psychology, 25(1), 27-40.

Moliner, P. (1996). Images et représentations sociales. Grenoble, France: PUG.

Moliner, P. (Ed.). (2001). Dynamique des représentations sociales. Grenoble, France: PUG.

Moliner, P., \& Vidal, J. (2003). Stéréotype de la catégorie et noyau de la représentation sociale. Revue Internationale de Psychologie Sociale, 16(1), 157-175.

Moreira, A. S. P. (Ed.). (2005). Anais da IV Jornada Internacional e II Conferência Brasileira sobre Representações Sociais: Teoria e abordagens metodológicas. João Pessoa, PB: Universidade Federal da Paraíba.

Moscovici, S. (1961). La psychanalyse, son image et son public. Paris: PUF.

Nascimento-Schulze, C. M., \& Camargo, B. V. (Eds.). (2001). Anais da II Jornada Internacional sobre Representações Sociais: Questões metodológicas. Florianópolis, SC: Editora da Universidade Federal de Santa Catarina.

Rouquette, M.-L. (2005). As representações sociais no quadro geral do pensamento social. In A. S. P. Moreira, B. V. Camargo, J. C. Jesuíno, \& S. M. Nóbrega (Eds.), Perspectivas teóricometodológicas em representações sociais (pp. 189-199). João Pessoa, PB: Editora da Universidade Federal da Paraíba.

Sá, C. P. (1996). Núcleo central das representações sociais. Petrópolis, RJ: Vozes.

Santos, N. C. dos, \& Meneghin, P. (2006). Concepções dos alunos de graduação em enfermagem sobre o envelhecimento. Revista da Escola de Enfermagem da USP, 40(2), 151-159.

Tafani, E. (1997). Attitudes et représentations sociales: de l'ancrage psychologique à l'ancrage sociologique. Unpublished doctoral dissertation, Université de Provence, Aix-en-Provence, France.

Vergès, P. (1992). L'évocation de l'argent: une méthode pour la définition du noyau central de la représentation. Bulletin de Psychologie, 45(405), 203-209.
Vergès, P. (2005). Os questionários para análise das representações sociais. In A. S. P. Moreira, B. V. Camargo, J. C. Jesuíno, \& S. M. Nóbrega (Eds.), Perspectivas teórico-metodológicas em representações sociais (pp. 201-228). João Pessoa, PB: Editora da Universidade Federal da Paraíba.

Vergès, P., Scano, S., \& Junique, C. (2002). Ensembles de programmes permettant l'analyse des evocations. Aix en Provence, France: Université de Provence.

Wachelke, J. F. R. (2007). Efeitos de instruções de questões abertas na ativação de elementos de representações sociais. Dissertação de Mestrado não-publicada, Universidade Federal de Santa Catarina, Florianópolis, SC.

Wachelke, J. F. R., Camargo, B. V., Hazan, J. V., Soares, D. R., Oliveira, L. T. P., \& Reynaud, P. D. (2007). Princípios organizadores da representação social do envelhecimento: Estudo realizado em ambiente de internet [Resumo]. In V Jornada Internacional e III Conferência Brasileira sobre Representações Sociais: Anais. Brasília, DF: Universidade de Brasília. Retrieved November 3, 2007, from http://www.vjirs.com.br

Wagner, W. (1998). Sócio-gênese e características das representações sociais. In A. S. P. Moreira \& D. C. de Oliveira (Eds.), Estudos interdisciplinares de representação social (pp. 3-25). Goiânia, GO: AB.

Wolter, R. P., \& Gurrieri, C. (2007). Classificação estrutural de diferentes formas do pensamento social. In V Jornada Internacional e III Conferência Brasileira sobre Representações Sociais: Anais. Brasília, DF: Universidade de Brasília. Retrieved November 20, 2007, from http://www.vjirs.com.br 